\title{
Comparison of Apixaban and Low Molecular Weight Heparin in Preventing Deep Venous Thrombosis after Total Knee Arthroplasty in Older Adults
}

\author{
Hui Jiang*, Jia Meng*, Ting Guo, Jian-ning Zhao, Yi-cun Wang, Jun Wang, Yang Qiu, and Hao Ding \\ Department of Orthopedics, Jinling Hospital, Nanjing Clinical School of the Second Military Medical University, Nanjing, Jiangsu, China.
}

\begin{abstract}
Purpose: To compare the effect of apixaban and low molecular weight heparin (LMWH) in the prevention and treatment of deep venous thrombosis (DVT) after total knee arthroplasty in older adult patients.

Materials and Methods: A total of 220 patients (average age of $67.8 \pm 6.4$ years) undergoing total knee arthroplasty were randomly selected as research subjects and were divided into apixaban and LMWH groups (110 in each group).

Results: The incidence of DVT was lower in the apixaban group than in the LMWH group (5.5\% vs. 20.0\%, $p=0.001)$. Activated partial thromboplastin times $(35.2 \pm 3.6 \mathrm{sec}$ vs. $33.7 \pm 2.2 \mathrm{sec}, p=0.010$; $37.8 \pm 4.6 \mathrm{sec}$ vs. $34.1 \pm 3.2 \mathrm{sec}, p<0.001 ; 39.6 \pm 5.1 \mathrm{sec}$ vs. $35.7 \pm 3.0$ sec, $p=0.032$ ) and prothrombin times ( $14.0 \pm 1.0 \mathrm{sec}$ vs. $12.8 \pm 0.9 \mathrm{sec}, p<0.001 ; 14.5 \pm 1.2 \mathrm{sec}$ vs. $13.0 \pm 1.1 \mathrm{sec}, p<0.001 ; 15.3 \pm 1.4 \mathrm{sec}$ vs. $13.2 \pm 1.3 \mathrm{sec}, p=0.009)$ in the apixaban group at 1 week after surgery, 3 weeks after surgery, and the end of treatment were higher than those in the LMWH group. Platelet and fibrinogen levels in the apixaban group were lower than those of the LMWH group. Also, capillary plasma viscosity and erythrocyte aggregation in the apixaban group at 1 week after surgery, 3 weeks after surgery, and the end of treatment were lower than those in the LMWH group.

Conclusion: Apixaban, which elicits fewer adverse reactions and is safer than LMWH, exhibited better effects in the prevention and treatment of DVT after total knee arthroplasty in older adults.
\end{abstract}

Key Words: Apixaban, low molecular weight heparin, total knee arthroplasty, deep venous thrombosis

\section{INTRODUCTION}

With aging of the global population, the incidence of joint diseases in older adults has increased year by year. Total knee ar-

Received: January 22, 2019 Revised: April 23, 2019

Accepted: May 9, 2019

Co-corresponding authors: Ting Guo, PhD, Department of Orthopedics, Jinling Hospital, Nanjing Clinical School of the Second Military Medical University, No. 305 Zhongshan East Road, Nanjing 210002, Jiangsu, China.

Tel: 86-025-80860015, Fax: 86-025-80860015, E-mail: guoting439h@163.com and Jian-ning Zhao, PhD, Department of Orthopedics, Jinling Hospital, Nanjing Clinical School of the Second Military Medical University, No. 305 Zhongshan East Road, Nanjing 210002, Jiangsu, China.

Tel: 86-025-80860015, Fax: 86-025-80860015, E-mail: zhaojianning578h@163.com

*Hui Jiang and Jia Meng contributed equally to this work.

-The authors have no potential conflicts of interest to disclose.

(C) Copyright: Yonsei University College of Medicine 2019

This is an Open Access article distributed under the terms of the Creative Commons Attribution Non-Commercial License (https://creativecommons.org/licenses/ by-nc/4.0) which permits unrestricted non-commercial use, distribution, and reproduction in any medium, provided the original work is properly cited. throplasty is one of the main methods of treating knee joint diseases. ${ }^{1,2}$ Although total knee arthroplasty can significantly improve the quality of life and walking ability of older adult patients, the risk of postoperative deep venous thrombosis (DVT) is high in these patients: a study has reported that the incidence of DVT after total knee arthroplasty is about $5-22 \% .{ }^{3}$ In recent years, due to the increase of total knee arthroplasty surgeries in older adult patients, the incidence of DVT has also followed an increasing trend. ${ }^{4}$

The treatment of anticoagulant drugs can significantly reduce the risk of postoperative DVT. ${ }^{5}$ Low molecular weight heparin (LMWH) is a commonly used medicine for the prevention and treatment of DVT after orthopedics surgery. A study has reported that LMWH is effective and can significantly reduce the incidence of DVT within 3 months after total knee arthroplasty. ${ }^{6}$ However, LMWH also has many limitations, especially in older adult patients discharged from the hospital. For example, the subcutaneous injection method is complicated, medication compliance is poor, blood coagulation function needs to be 
regularly monitored, and so on. ${ }^{7}$ In recent years, new anticoagulant oral preparations have been developed. Apixaban is a new potent oral FXa inhibitor that can rapidly combine with FXa and transform prothrombin into thrombin., ${ }^{8,9}$ One study has shown that apixaban can significantly reduce the incidence of DVT and the associated mortality after orthopedic surgery. ${ }^{10}$ At present, there are few clinical studies comparing the efficacy of apixaban and $\mathrm{LMWH}$ in preventing and treating DVT after total knee arthroplasty in older adult patients. Therefore, this research sought to compare the efficacy of apixaban and LMWH in older adult patients undergoing total knee arthroplasty in order to provide an experimental and theoretical basis for the development of clinical anticoagulant strategies therein.

\section{MATERIALS AND METHODS}

\section{General information}

A total of 220 older adult patients undergoing total knee arthroplasty admitted to our hospital from January 2015 to November 2017 were selected. They were randomly divided into apixaban and LMWH groups (110 patients in each group). $\mathrm{Pa}-$ tients in the apixaban group were treated with apixaban orally at $12 \mathrm{~h}$ after surgery, twice a day, $2.5 \mathrm{mg}$ each time. ${ }^{11}$ Patients in the LMWH group were given LMWH (purchased from GlaxoSmithKline Co., Ltd., Tianjin, China) via hypodermic injection at $12 \mathrm{~h}$ after surgery, $4000 \mathrm{IU}$ per day. ${ }^{12}$ The doses of apixaban and $\mathrm{LMWH}$ were not adjusted according to indicators such as activated partial thromboplastin time (APTT). The course of treatment in the two groups both lasted for 5 weeks. Alleviating analgesia and early ambulation were routinely conducted for postoperative patients. This study was approved by the Ethics Committee of Jinling Hospital (2016NZKY-020-02). All patients or their families signed informed consent.

The inclusion criteria were older adults ( $>60$ years old), patients with total knee arthroplasty indications, patients without surgical contraindications, and patients with no history of DVT before surgery. Exclusion criteria were patients with malignant tumors; patients with liver, kidney, heart, lung, or other important organ dysfunction; patients with blood coagulation dysfunction; patients whose preoperative ultrasonography of blood vessels revealed DVT; patients who were allergic to the drugs being studied in this research; patients with a history of mental illness; patients who refused to provide informed consent; and patients who did not meet the experimental ethical standards.

\section{Observation index}

The visual analogue scale (VAS) scoring system was used to evaluate pain experienced by patients before surgery and at the end of treatment. VAS scores ranged from 0 to 10 , with 0 indicating no pain and 10 indicating severe pain.
The incidence of DVT between the two groups within 3 months after surgery were compared. The clinical manifestations of symptomatic DVT were dark purple skin, elevated skin temperature, swollen lower limbs, shallow vein engorgement, and tenderness in the femoral triangle, which was confirmed by color doppler ultrasound. If there were no symptoms, color doppler ultrasound was used to examine for DVT. The patients were re-checked by ultrasound once every 2 weeks, with follow up by outpatient appointment after discharge.

Blood coagulation function indexes in two groups were compared. APTT, prothrombin time (PT), platelets (PLT), and fibrinogen (FIB) were measured using a full-automated blood coagulation analyzer at 1 week after surgery, 3 weeks after surgery, and the end of treatment, and then averaged. Also, we compared hemodynamic indexes of the two groups, including capillary plasma viscosity and erythrocyte aggregation. Hemodynamic indexes were evaluated at 1 week after surgery, 3 weeks after surgery, and the end of treatment, and then averaged.

The movement ability and state of knee joint were compared between the two groups. The hospital for special surgery (HSS) knee joint scoring system was used to evaluate postoperative function of the knee joint at 1 week after surgery, 3 weeks after surgery, and the end of treatment, and mean values were calculated to compare patients in the two groups. The HSS scoring system comprises six main aspects, including pain, function, joint mobility, muscle strength, knee flexion deformity, and knee instability, with a total score of 100 points. The higher the score, the better the movement ability and state of the knee joint.

Adverse reactions in the two groups were compared. Postoperative drainage volume, bleeding events (cerebral hemorrhage, primae viae bleeding, and subcutaneous hemorrhage), and liver and kidney function were observed.

\section{Statistical analysis}

SPSS 20.0 statistical software (IBM Corp., Armonk, NY, USA) was used to analyze all data. Measurement data were expressed as a mean \pm standard deviation $(\overline{\mathrm{x}} \pm \mathrm{SD})$. The $t$ test was used for comparisons between groups, and paired t test was used for the comparison of indicators before and after intervention. The comparison of indexes at different time points was analyzed by ANOVA of repeated measurements combined with post-Bonferroni test. Enumeration data are expressed as percentages, and the $\chi^{2}$ test was used for comparison between groups. There was a significant difference at $p<0.05$.

\section{RESULTS}

\section{Comparison of basic data}

Between the two study groups, there were no significant differences in gender, age, body mass index, underlying disease, duration of operation, discharge time, ratio of general anesthesia to intraspinal anesthesia, expanded medical structure num- 
Table 1. Comparison of Basic Data between Groups

\begin{tabular}{|c|c|c|c|c|}
\hline Variables & Apixaban group $(n=110)$ & LMWH group $(n=110)$ & $t / \chi^{2}$ & $p$ value \\
\hline Gender (male/female) & $62 / 48$ & $52 / 58$ & 0.910 & 0.340 \\
\hline Age (yr) & $68.7 \pm 5.7$ & $70.2 \pm 6.1$ & 0.311 & 0.771 \\
\hline BMI $\left(\mathrm{kg} / \mathrm{m}^{2}\right)$ & $24.5 \pm 3.2$ & $25.1 \pm 3.5$ & 0.219 & 0.837 \\
\hline Hypertension (n) & 11 & 17 & 1.725 & 0.189 \\
\hline Hyperlipidemia (n) & 4 & 6 & 0.110 & 0.740 \\
\hline Diabetes (n) & 7 & 3 & 0.990 & 0.320 \\
\hline Duration of operation (min) & $110.6 \pm 23.5$ & $105.3 \pm 19.7$ & 1.279 & 0.204 \\
\hline Discharge time (day) & $12.5 \pm 2.4$ & $12.2 \pm 1.9$ & 0.727 & 0.469 \\
\hline General anesthesia/intraspinal anesthesia (n) & $40 / 15$ & $37 / 18$ & 0.390 & 0.533 \\
\hline Expanded medical structure number (n) & 24 & 28 & 0.584 & 0.445 \\
\hline Intraoperative blood loss (mL) & $119.5 \pm 36.8$ & $108.7 \pm 31.4$ & 1.656 & 0.101 \\
\hline Blood transfusion volume (mL) & $254.3 \pm 77.5$ & $276.5 \pm 80.5$ & 1.473 & 0.144 \\
\hline Postoperative analgesia satisfaction (yes/no) & $51 / 4$ & $52 / 3$ & 0.153 & 0.696 \\
\hline
\end{tabular}

$\mathrm{BMI}$, body mass index; LMWH, low molecular weight heparin.

ber, intraoperative blood loss, blood transfusion volume, and postoperative analgesia satisfaction (all $p>0.05$ ) (Table 1).

\section{Comparison of VAS scores}

There was no significant difference in preoperative VAS scores between the two groups. There was also no significant difference in VAS scores between the two groups at the end of treatment. VAS score of the end of the treatment, however, was significantly lower than that of before surgery in both groups (Table 2).

\section{Comparison of the incidence of DVT}

Vascular ultrasound revealed DVT in 6 patients in the apixaban group, including three in the iliac vein, one in the femoral vein, and two in the popliteal vein. There were 22 cases of DVT in the LMWH group, including 12 in the iliac vein, six in the femoral vein, and four in the popliteal vein. There was a significant difference in the incidences of DVT between the two groups (5.5\% vs. $20.0 \%, \chi^{2}=410.480, p=0.001$ ) (Fig. 1 ).

\section{Comparison of blood coagulation function indexes}

ANOVA of repeated measurements revealed significant differences in APTT, PT, PLT, and FIB at different time points. APTT and PT indexes were increased and PLT and FIB indexes were decreased at 1 week after surgery, 3 weeks after surgery, and the end of treatment in two groups, compared to before surgery. APTT and PT indexes in the apixaban group were higher than those in the LMWH group at 1 week after surgery, 3 weeks after surgery, and the end of treatment, while PLT and FIB indexes were lower than those in the LMWH group (Table 3, Fig. 2).

\section{Comparison of hemorheology indexes}

ANOVA of repeated measurements showed significant differences in capillary plasma viscosity and erythrocyte aggregation at different time points. Capillary plasma viscosity and erythrocyte aggregation index values at 1 week after surgery, 3 weeks
Table 2. Comparison of Visual Analogue Scale Scores before Surgery and at the End of Treatment

\begin{tabular}{lcccc}
\hline \multicolumn{1}{c}{ Group } & $\begin{array}{c}\text { Before } \\
\text { surgery }\end{array}$ & $\begin{array}{c}\text { End } \\
\text { of the treatment }\end{array}$ & $\mathbf{t}$ & $\boldsymbol{p}$ value \\
\hline Apixaban group $(\mathrm{n}=110)$ & $4.5 \pm 0.9$ & $3.6 \pm 0.5$ & 6.483 & $<0.001$ \\
LMWH group $(\mathrm{n}=110)$ & $4.7 \pm 1.0$ & $3.8 \pm 0.7$ & 5.468 & $<0.001$ \\
$\mathrm{t}$ & 1.102 & 1.724 & & \\
$p$ & 0.273 & 0.088 & & \\
\hline p value & & & & \\
\hline
\end{tabular}

LMWH, low molecular weight heparin.

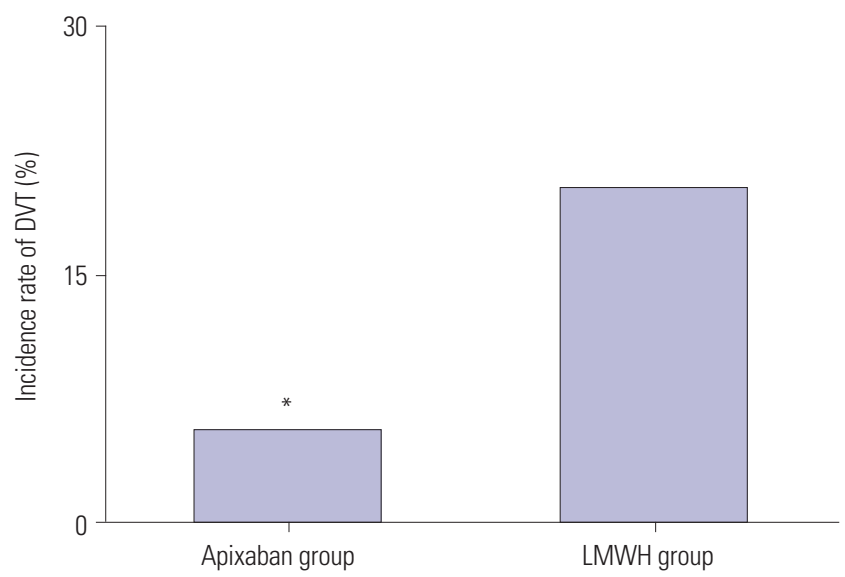

Fig. 1. Comparison of the incidence of DVT between the study groups. Compared with the LMWH group, ${ }^{*} p<0.05$. LMWH, low molecular weight heparin; DVT, deep venous thrombosis.

after surgery, and the end of treatment in two groups were significantly lower than those before surgery. Capillary plasma viscosity and erythrocyte aggregation in the apixaban group were significantly lower than those in the LMWH group at 1 week after surgery, 3 weeks after surgery, and the end of treatment (Tables 4 and 5, Figs. 3 and 4).

\section{Comparison of HSS scores}

The HSS scores for patients in the apixaban group at 1 week, 3 
Table 3. Comparison of Blood Coagulation Function Indexes

\begin{tabular}{|c|c|c|c|c|}
\hline $\begin{array}{l}\text { Blood coagulation } \\
\text { function indexes }\end{array}$ & Before surgery & $\begin{array}{c}\text { At } 1 \text { week } \\
\text { after surgery }\end{array}$ & $\begin{array}{l}\text { At } 3 \text { weeks } \\
\text { after surgery }\end{array}$ & $\begin{array}{l}\text { At the end } \\
\text { of treatment }\end{array}$ \\
\hline \multicolumn{5}{|l|}{ APTT (sec) } \\
\hline Apixaban group $(n=110)$ & $30.9 \pm 3.9$ & $35.2 \pm 3.6^{*+}$ & $37.8 \pm 4.6^{*+}$ & $39.6 \pm 5.1^{*+}$ \\
\hline LMWH group (n=110) & $31.4 \pm 4.8$ & $33.7 \pm 2.2^{*}$ & $34.1 \pm 3.2^{*}$ & $35.7 \pm 3.0^{*}$ \\
\hline$p$ value & 0.895 & 0.010 & $<0.001$ & 0.032 \\
\hline \multicolumn{5}{|l|}{ PT (sec) } \\
\hline Apixaban group ( $n=110)$ & $12.4 \pm 1.3$ & $14.0 \pm 1.0^{* \dagger}$ & $14.5 \pm 1.2^{* \dagger}$ & $15.3 \pm 1.4^{* \dagger}$ \\
\hline LMWH group $(n=110)$ & $12.2 \pm 1.5$ & $12.8 \pm 0.9^{*}$ & $13.0 \pm 1.1^{*}$ & $13.2 \pm 1.3^{*}$ \\
\hline$p$ value & 0.870 & $<0.001$ & $<0.001$ & 0.009 \\
\hline \multicolumn{5}{|l|}{$\operatorname{PLT}\left(\times 10^{9} / \mathrm{L}\right)$} \\
\hline Apixaban group $(\mathrm{n}=110)$ & $220.5 \pm 38.5$ & $179.6 \pm 15.8^{* \dagger}$ & $169.4 \pm 18.6^{* \dagger}$ & $165.4 \pm 21.7^{*+}$ \\
\hline LMWH group ( $\mathrm{n}=110)$ & $211.9 \pm 34.6$ & $190.6 \pm 17.4^{*}$ & $188.8 \pm 17.4^{*}$ & $185.2 \pm 18.2^{*}$ \\
\hline$p$ value & 0.788 & 0.001 & $<0.001$ & 0.029 \\
\hline \multicolumn{5}{|l|}{$\mathrm{FIB}(\mathrm{g} / \mathrm{L})$} \\
\hline Apixaban group (n=110) & $3.7 \pm 0.5$ & $3.1 \pm 0.4^{* \dagger}$ & $2.9 \pm 0.5^{* \dagger}$ & $2.7 \pm 0.4^{* \dagger}$ \\
\hline LMWH group $(n=110)$ & $3.8 \pm 0.6$ & $3.4 \pm 0.6^{*}$ & $3.3 \pm 0.6^{*}$ & $3.2 \pm 0.5^{*}$ \\
\hline$p$ value & 0.835 & 0.003 & $<0.001$ & 0.016 \\
\hline
\end{tabular}

APTT, activated partial thromboplastin time; LMWH, low molecular weight heparin; PT, prothrombin time; PLT, platelets; FIB, fibrinogen. Compared with before surgery within the same group, ${ }^{*} p<0.05$; compared with the LMWH group, ${ }^{\dagger} p<0.05$.
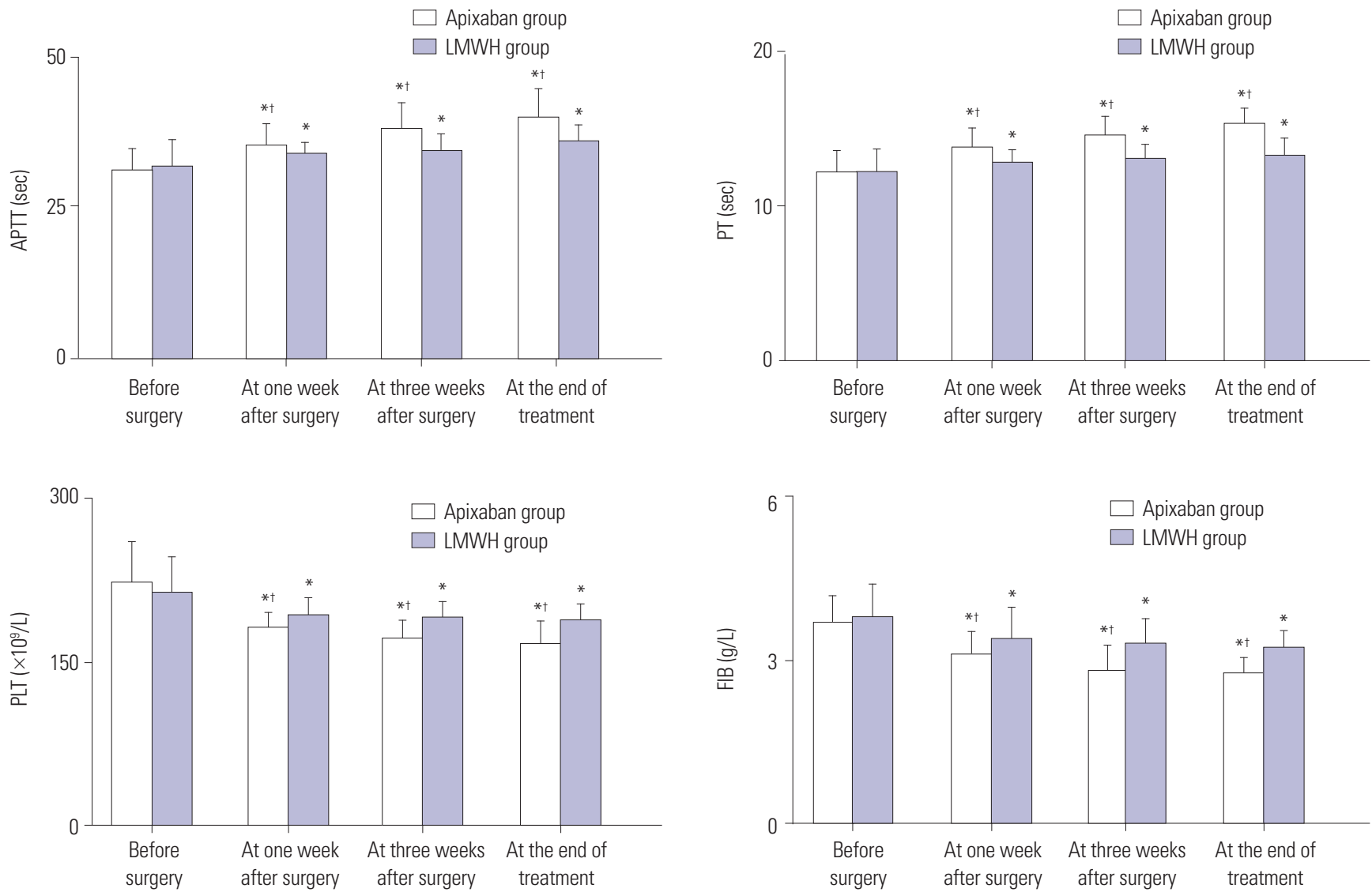

Fig. 2. Comparison of APTT, PT, PLT, and FIB indexes between the study groups. Compared with before surgery within the same group, ${ }^{*} p<0.05$; compared with the LMWH group, ${ }^{\dagger} p<0.05$. APT, activated partial thromboplastin time; PT, prothrombin time; PLT, platelets; FIB, fibrinogen; LMWH, low molecular weight heparin. 
Table 4. Comparison of Capillary Plasma Viscosity

\begin{tabular}{lcccc}
\hline \multicolumn{1}{c}{ Group } & Before intervention & $\mathbf{1}$ week after intervention & $\mathbf{3}$ weeks after intervention & $\mathbf{5}$ weeks after intervention \\
\hline Apixaban group $(\mathrm{n}=110)$ & $1.3 \pm 0.3$ & $1.0 \pm 0.3$ & $0.9 \pm 0.2$ & $0.8 \pm 0.2$ \\
$\mathrm{LMWH}$ group $(\mathrm{n}=110)$ & $1.4 \pm 0.4$ & $1.2 \pm 0.4$ & $1.1 \pm 0.3$ & $1.0 \pm 0.2$ \\
$\mathrm{t}$ & 0.511 & 2.966 & 4.114 & 2.638 \\
$p$ value & 0.620 & 0.004 & $<0.001$ & 0.011 \\
\hline
\end{tabular}

LMWH, low molecular weight heparin.

Table 5. Comparison of Erythrocyte Aggregation Index

\begin{tabular}{lcccc}
\hline \multicolumn{1}{c}{ Group } & Before intervention & 1 week after intervention & 3 weeks after intervention & 5 weeks after intervention \\
\hline Apixaban group $(n=110)$ & $2.0 \pm 0.3$ & $1.5 \pm 0.3$ & $1.4 \pm 0.3$ & $1.3 \pm 0.2$ \\
LMWH group $(n=110)$ & $2.1 \pm 0.4$ & $1.8 \pm 0.4$ & $1.7 \pm 0.3$ & $1.6 \pm 0.3$ \\
$t$ & 0.346 & 4.450 & 5.244 & 2.882 \\
$p$ value & 0.746 & $<0.001$ & $<0.001$ & 0.011 \\
\hline
\end{tabular}

LMWH, low molecular weight heparin.

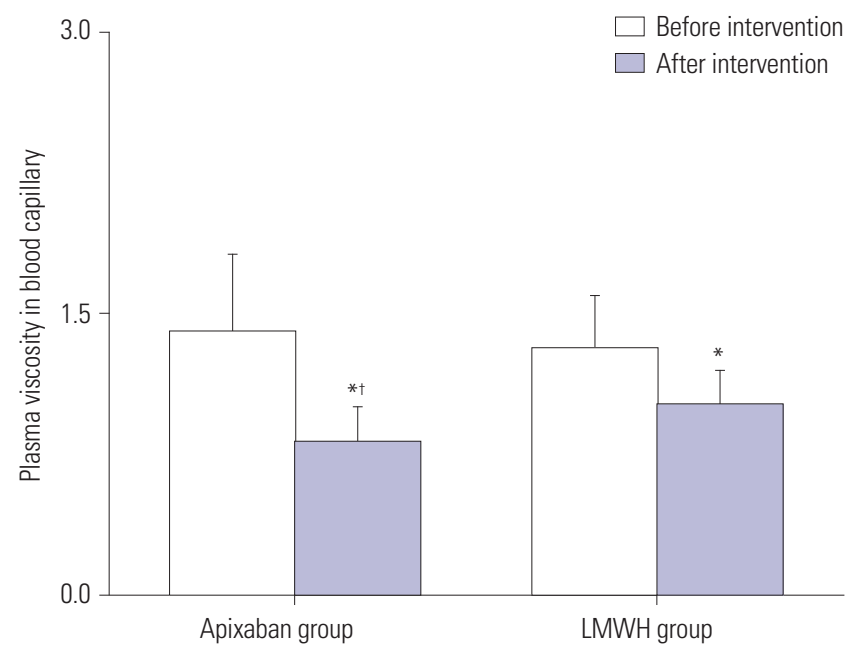

Fig. 3. Comparison of capillary plasma viscosity at the end of treatment between the study groups. Compared with the same group before intervention, ${ }^{*} p<0.05$; compared with the LMWH group after intervention, ${ }^{\dagger} p<0.05$. LMWH, low molecular weight heparin.

weeks, and 5 weeks after surgery were $82.4 \pm 6.5,85.7 \pm 7.1$, and 89.5 \pm 8.4 , respectively. The HSS scores for patients in the LMWH group at 1 week, 3 weeks, and 5 weeks after surgery were $80.9 \pm$ $6.2,84.1 \pm 6.9$, and $87.4 \pm 7.9$, respectively. ANOVA of repeated measurements showed that there were no significant differences in HSS scores at the different time points between groups (Table 6).

\section{Comparison of adverse reactions}

No deaths occurred during follow up in either group, and no liver and kidney function damage occurred during medication. In the LMWH group, some patients experienced ecchymosis and allergic reactions at the injection site, which recovered after active symptomatic treatment. Some patients in the apixaban group complained of nausea and anemia, and recovered significantly after symptomatic treatment. Compared with the LMWH group, postoperative drainage volume in the apixaban group was significantly lower $(215.7 \pm 20.5 \mathrm{~mL}$ vs. $298.2 \pm 26.2$

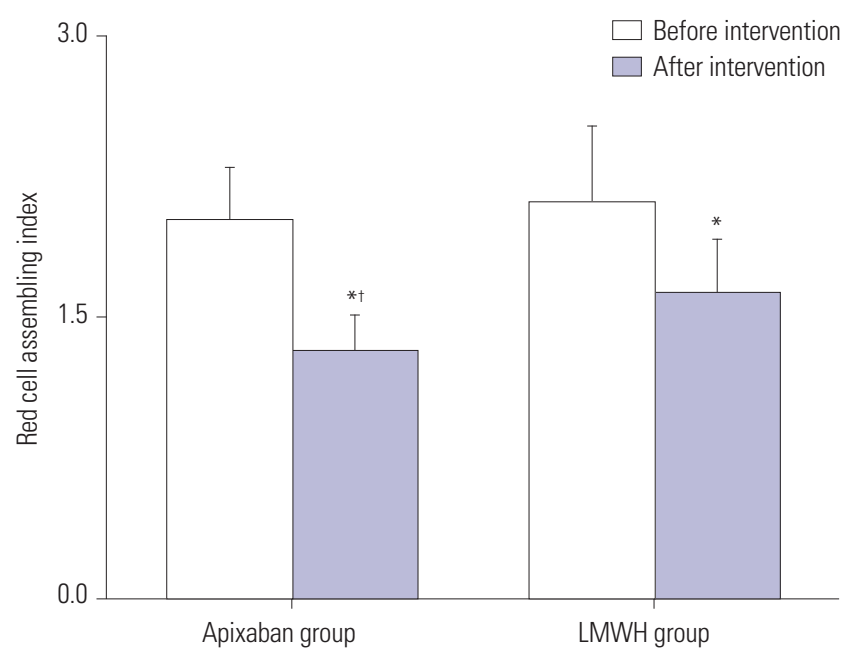

Fig. 4. Comparison of erythrocyte aggregation at the end of treatment between the study groups. Compared with the same group before intervention, ${ }^{*} p<0.05$; compared with the LMWH group after intervention, ${ }^{\dagger} p<0.05$. LMWH, low molecular weight heparin.

$\mathrm{mL}, \mathrm{t}=4.295, p=0.013)$. There was no significant difference in the incidence of bleeding events between groups (10.9\% vs. $5.5 \%, \chi^{2}=1.089, p=0.297$ ) (Fig. 5).

\section{DISCUSSION}

DVT is a common complication after clinical orthopedic surgery, especially in older adult patients undergoing artificial joint arthroplasty. The formation of DVT can lead to organ dysfunction, such as pulmonary embolism and so on, which is one of the major causes of perioperative death and seriously threatens the life and health of patients. ${ }^{11}$ One study has reported that the incidence of DVT after artificial joint arthroplasty can reach up to $30 \%$, if no corresponding measures are taken. ${ }^{12}$ The high incidence of DVT in older adult patients after artificial joint arthroplasty may be associated with more underlying diseases in older adult patients, physiological function degeneration, 
blood in a hypercoagulable state, a lack of postoperative functional exercise, surgical injury to the vascular endothelium, and activation of the coagulation-fibrinolytic system. ${ }^{13,14}$

At present, the prevention and treatment of DVT after artificial joint arthroplasty have primarily relied on drug therapy with LMWH, unfractionated heparin, and vitamin K antagonists. Although these drugs have a desirable effect, there are also many adverse reactions. ${ }^{15,16}$ Therefore, it is of great significance to find a safe and effective drug to prevent DVT after artificial joint arthroplasty in older adult patients. LMWH has been widely used as a thromboprophylaxis drug after total knee arthroplasty. LMWH can target complex enzymes in the internal and external pathways of the coagulation cascade, and it can also be combined with anticoagulant enzymes to enhance its effect. ${ }^{17}$ However, research has shown that it is inconvenient for patients undergoing total hip arthroplasty, especially for older adults, given its route of administration. ${ }^{18}$ Apixaban, a new type of oral anticoagulant, has a simpler route of administration than LMWH. Through the selective inhibition of the coagulation FXa, apixaban can block endogenous and exogenous pathways generated by thrombin and can inhibit thrombus formation. ${ }^{19}$ In recent years, a study revealed that apixaban has a certain effect in the prevention and treatment of DVT after surgery of hip fracture. ${ }^{20}$ However, the differences in the prevention of DVT between apixaban and LMWH in older adult patients undergoing total knee arthroplasty have remained unclear. The results of the present study showed a significantly lower incidence of DVT with apixaban than with LMWH. The study of Lanitis, et al. ${ }^{21}$ also suggested that apixa-

Table 6. Comparison of Hospital for Special Surgery Scores

\begin{tabular}{lccc}
\hline \multicolumn{1}{c}{ Group } & $\begin{array}{c}\mathbf{1} \text { week } \\
\text { after surgery }\end{array}$ & $\begin{array}{c}\mathbf{3} \text { weeks } \\
\text { after surgery }\end{array}$ & $\begin{array}{c}\mathbf{5} \text { weeks } \\
\text { after surgery }\end{array}$ \\
\hline Apixaban group $(\mathrm{n}=110)$ & $82.4 \pm 6.5$ & $85.7 \pm 7.1$ & $89.5 \pm 8.4$ \\
LMWH group $(\mathrm{n}=110)$ & $80.9 \pm 6.2$ & $84.1 \pm 6.9$ & $87.4 \pm 7.9$ \\
$\mathrm{t}$ & 1.238 & 1.199 & 1.351 \\
$\mathrm{p}$ & 0.218 & 0.233 & 0.178 \\
\hline
\end{tabular}

LMWH, low molecular weight heparin.

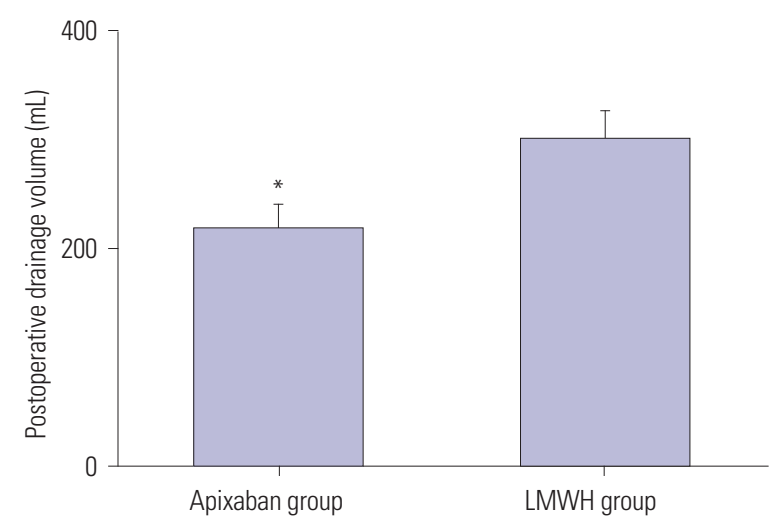

ban had obvious advantages in the prevention and treatment of DVT, compared with LMWH. Notwithstanding, previous research has reported that there was no significant difference in the incidence of DVT between the apixaban group and the LMWH group, which may be due to the subject selection (older adult patients), different sample size, and patient compliance in this study. ${ }^{10}$

In terms of blood coagulation function and hemorheology indices, the results of this research showed that blood coagulation function and hemorheology after intervention in the apixaban group were significantly better than those in the LMWH group. In the aspect of adverse drug reactions, postoperative drainage volumes in the apixaban group were significantly lower than those in the LMWH group. While the incidence of bleeding events in the apixaban group was higher than that in the LMWH group, the difference was not statistically significant. These findings further indicate that apixaban is more effective than LMWH in the prevention of DVT after total knee arthroplasty in older adult patients, as it elicits fewer adverse reactions and is safer. The results of a study on 520 acute symptomatic DVT patients who received different doses of apixaban also showed that apixaban was effective in reducing DVT and was safe. ${ }^{22}$

There are certain limitations in this research. Although digital subtraction angiography is the "gold standard" for the diagnosis of DVT, in view of its large trauma and high cost, vascular doppler ultrasound examination was used in this study. Also, the sample size enrolled in this study was small, and this study reflects results at a single center. Further studies need to collect and increase the number of cases and conduct prospective studies of multi-center follow-up control, confirming changes in index values at multiple time points, studying the risk of thrombosis over a longer period of time, and studying drugs at different doses.

In summary, the efficacy and safety of apixaban in the prevention of DVT after total knee arthroplasty in older adult patients was better than that of LMWH. Apixaban, as an oral agent, is an effectively antithrombotic and anticoagulant drug

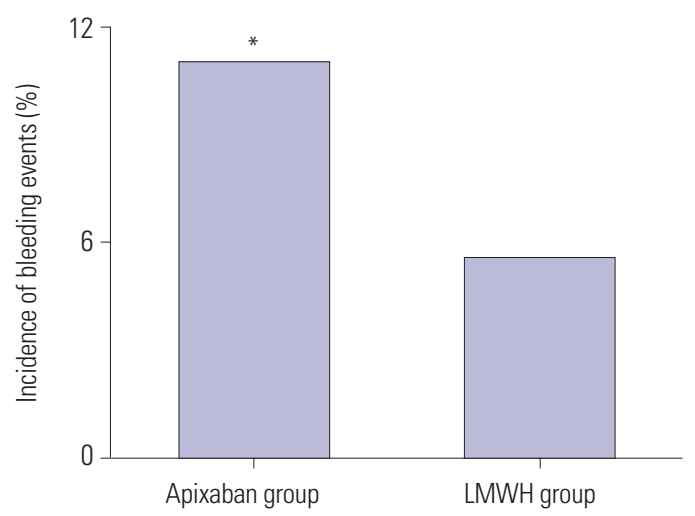

Fig. 5. Comparison of the postoperative drainage volume and the incidence of bleeding events between the study groups. Compared with the LMWH group, ${ }^{*} p<0.05$. LMWH, low molecular weight heparin. 
worth promoting in the treatment of DVT after artificial joint arthroplasty.

\section{ACKNOWLEDGEMENTS}

This work was supported by the Chinese Medical Doctor Association-Special Fund for Thrombosis Prevention after Major Orthopedics Surgery (No. 2015COS0810) and Nanjing General Hospital Subject (No. 2017003).

\section{AUTHOR CONTRIBUTIONS}

Conceptualization: Hao Ding. Data curation: Hao Ding and Yi-cun Wang. Formal analysis: Yang Qiu. Funding acquisition: Jun Wang. Investigation: Hui Jiang. Methodology: Hui Jiang. Project administration: Ting Guo. Resources: Jian-ning Zhao. Software: Ting Guo. Supervision: Jia Meng. Validation: Jian-ning Zhao. Visualization: Yang Qiu. Writing_original draft: Hui Jiang. Writing_review \& editing: Jia Meng.

\section{ORCID iDs}

$\begin{array}{ll}\text { Hui Jiang } & \text { https://orcid.org/0000-0002-0419-8128 } \\ \text { Jia Meng } & \text { https://orcid.org/0000-0002-8121-8882 } \\ \text { Ting Guo } & \text { https://orcid.org/0000-0002-6417-999X } \\ \text { Jian-ning Zhao } & \text { https://orcid.org/0000-0002-0093-4423 } \\ \text { Yi-cun Wang } & \text { https://orcid.org/0000-0003-4067-1637 } \\ \text { Jun Wang } & \text { https://orcid.org/0000-0003-2557-4978 } \\ \text { Yang Qiu } & \text { https://orcid.org/0000-0003-2537-882X } \\ \text { Hao Ding } & \text { https://orcid.org/0000-0003-2688-3852 }\end{array}$

\section{REFERENCES}

1. Bonutti PM, Sodhi N, Patel YH, Sultan AA, Khlopas A, Chughtai $\mathrm{M}$, et al. Novel venous thromboembolic disease (VTED) prophylaxis for total knee arthroplasty-aspirin and fish oil. Ann Transl Med 2017;5(Suppl 3):S30.

2. Zhou LY, Gu W, Liu Y, Ma ZL. Effects of inhalation anesthesia vs. total intravenous anesthesia (TIVA) vs. spinal-epidural anesthesia on deep vein thrombosis after total knee arthroplasty. Med Sci Monit 2018;24:67-75.

3. Falck-Ytter Y, Francis CW, Johanson NA, Curley C, Dahl OE, Schulman S, et al. Prevention of VTE in orthopedic surgery patients. Antithrombotic Therapy and Prevention of Thrombosis, 9th ed: American College of Chest Physicians Evidence-Based Clinical Practice Guidelines. Chest 2012;141(2 Suppl):e278S-e325S.

4. Wakabayashi H, Hasegawa M, Niimi R, Yamaguchi T, Naito Y, Sudo A. The risk factor of preoperative deep vein thrombosis in patients undergoing total knee arthroplasty. J Orthop Sci 2017;22:698-702.

5. Zou Y, Tian S, Wang Y, Sun K. Administering aspirin, rivaroxaban and low-molecular-weight heparin to prevent deep venous thrombosis after total knee arthroplasty. Blood Coagul Fibrinolysis 2014;25:660-4.

6. Warwick D, Friedman RJ, Agnelli G, Gil-Garay E, Johnson K, FitzGerald G, et al. Insufficient duration of venous thromboembolism prophylaxis after total hip or knee replacement when compared with the time course of thromboembolic events: findings from the Global Orthopaedic Registry. J Bone Joint Surg Br 2007;89: 799-807.

7. Beyer-Westendorf J, Lützner J, Donath L, Tittl L, Knoth H, Radke
OC, et al. Efficacy and safety of thromboprophylaxis with low-molecular-weight heparin or rivaroxaban in hip and knee replacement surgery: findings from the ORTHO-TEP registry. Thromb Haemost 2013;109:154-63.

8. Aryal MR, Pandit A, Ghimire S, Pathak R, Karmacharya P, Poudel $\mathrm{DR}$, et al. Thromboprophylaxis with apixaban and the risk of pulmonary embolism in patients undergoing knee replacement surgery. J Community Hosp Intern Med Perspect 2015;5:27889.

9. King DA, Pow RE, Dickison DM, Vale PR. Apixaban versus enoxaparin in the prevention of venous thromboembolism following total knee arthroplasty: a single-centre, single-surgeon, retrospective analysis. Intern Med J 2016;46:1030-7.

10. Lassen MR, Raskob GE, Gallus A, Pineo G, Chen D, Portman RJ. Apixaban or enoxaparin for thromboprophylaxis after knee replacement. N Engl J Med 2009;361:594-604.

11. Cafri G, Paxton EW, Chen Y, Cheetham CT, Gould MK, Sluggett J, et al. Comparative effectiveness and safety of drug prophylaxis for prevention of venous thromboembolism after total knee arthroplasty. J Arthroplasty 2017;32:3524-8.

12. Bala A, Huddleston JI 3rd, Goodman SB, Maloney WJ, Amanatullah DF. Venous thromboembolism prophylaxis after TKA: aspirin, warfarin, enoxaparin, or factor Xa inhibitors? Clin Orthop Relat Res 2017;475:2205-13.

13. Kang J, Jiang X, Wu B. Analysis of risk factors for lower-limb deep venous thrombosis in old patients after knee arthroplasty. Chin Med J (Engl) 2015;128:1358-62.

14. Kuperman EF, Schweizer M, Joy P, Gu X, Fang MM. The effects of advanced age on primary total knee arthroplasty: a meta-analysis and systematic review. BMC Geriatr 2016;16:41.

15. Pierce TP, Elmallah RK, Jauregui JJ, Cherian JJ, Mont MA. What's new in venous thromboembolic prophylaxis following total knee and total hip arthroplasty? An update. Surg Technol Int 2015;26: 234-7.

16. Lieberman JR, Hsu WK. Prevention of venous thromboembolic disease after total hip and knee arthroplasty. J Bone Joint Surg Am 2005;87:2097-112.

17. Lazo-Langner A, Fleet JL, McArthur E, Garg AX. Rivaroxaban vs. low molecular weight heparin for the prevention of venous thromboembolism after hip or knee arthroplasty: a cohort study. J Thromb Haemost 2014;12:1626-35.

18. O'Donnell M, Linkins LA, Kearon C, Julian J, Hirsh J. Reduction of out-of-hospital symptomatic venous thromboembolism by extended thromboprophylaxis with low-molecular-weight heparin following elective hip arthroplasty: a systematic review. Arch Intern Med 2003;163:1362-6.

19. Li X, Keshishian A, Hamilton M, Horblyuk R, Gupta K, Luo X, et al. Apixaban 5 and $2.5 \mathrm{mg}$ twice-daily versus warfarin for stroke prevention in nonvalvular atrial fibrillation patients: comparative effectiveness and safety evaluated using a propensity-scorematched approach. PLoS One 2018;13:e0191722.

20. Venker BT, Ganti BR, Lin H, Lee ED, Nunley RM, Gage BF. Safety and efficacy of new anticoagulants for the prevention of venous thromboembolism after hip and knee arthroplasty: a meta-analysis. J Arthroplasty 2017;32:645-52.

21. Lanitis T, Leipold R, Hamilton M, Rublee D, Quon P, Browne C, et al. Cost-effectiveness of apixaban versus low molecular weight heparin/vitamin k antagonist for the treatment of venous thromboembolism and the prevention of recurrences. BMC Health Serv Res 2017;17:74.

22. Lassen MR, Davidson BL, Gallus A, Pineo G, Ansell J, Deitchman D. The efficacy and safety of apixaban, an oral, direct factor Xa inhibitor, as thromboprophylaxis in patients following total knee replacement. J Thromb Haemost 2007;5:2368-75. 